\title{
PERCUTORES LÍTICOS DE LA PAMPA DEL DESIERTO DE ATACAMA (NORTE DE CHILE): TECNOLOGÍA, HUELLAS DE USO, DECORACIÓN Y TALLADORES
}

\author{
HAMMERSTONES FROM THE ATACAMA DESERT PAMPA \\ (NORTHERN CHILE): TECHNOLOGY, SIGNS OF WEAR AND TEAR \\ DECORATION AND KNAPPERS
}

\author{
Benjamín Ballester ${ }^{1}$ y Macarena Crisóstomo 2
}

\begin{abstract}
Podría decirse que la lítica es el material por excelencia en los estudios de cazadores recolectores en arqueología. Paradójicamente es muy poco lo que sabemos acerca de los artefactos involucrados en los procesos de producción de los instrumentos líticos, menos aún de los percutores duros, utilizados preferentemente en las etapas iniciales de su cadena operativa. Presentamos el análisis de un conjunto de percutores hechos sobre guijarros que forman parte de un extenso taller lítico ubicado en la pampa de Antofagasta, norte de Chile. Ahondaremos en sus aspectos tecnológicos, morfológicos, huellas de uso, soportes y decoración, para finalmente intentar discutir acerca de quiénes pudieron ser y de dónde provenían estos talladores. Un tema que nos trasladará finalmente hacia el océano y su litoral, junto a las estrategias de movilidad de los antiguos cazadores-recolectores marinos del desierto de Atacama. Palabras claves: percutores líticos, talladores, cazadores-recolectores marinos, desierto de Atacama.
\end{abstract}

Lithics could be said to be the materiality par excellence in the archaeological studies of hunter-gatherers. Paradoxically the knowledge we have about the artifacts involved in the production process of lithic instruments is scarce. Even less is known about hard hammerstones, employed mainly in the initial stages of their operational chain. We present the analysis of a complete hammerstone collection made of pebbles and cobbles from an extensive lithic workshop located in the pampa of Antofagasta, northern Chile. We will look closely into their technological and morphological aspects, as well as their use wear patterns, bases-forms and raw materials, in order to discuss who these knappers were and where they came from. A subject that would finally lead us to the ocean and its littoral, along with the mobility strategies of the ancient marine hunter-gatherers from the Atacama Desert.

Key words: Hammerstone, knappers, marine hunter-gatherers, Atacama Desert.

La lítica ha ocupado históricamente un lugar privilegiado en el estudio de los cazadores recolectores desde la arqueología. Tanto que podríamos decir que la piedra se ha convertido en su material por excelencia y la talla en una de las actividades que como arqueólogos más conocemos. Paradójicamente es muy poco lo que se ha escrito sobre las herramientas involucradas en los procesos de talla lítica, tanto percutores como retocadores. En Chile la carencia es aún más grande, sin que exista una publicación dedicada a su estudio o descripción.

En este trabajo se presenta el análisis de un conjunto de percutores líticos asociados a un extenso taller ubicado en la pampa de Antofagasta, en pleno corazón del desierto de Atacama. Si bien esta pampa es reconocida por la abundancia de talleres líticos, escasas investigaciones específicas se han publicado sobre ellos (Le Paige 1970), algunos como parte de estudios de impacto ambiental (Blanco et al. 2010;
Peralta et al. 2010). Sin embargo, Max Uhle (1916, 1917) en la década de 1910 ya los mencionaba al interior de Taltal, para él producto de la explotación de roca por cazadores-recolectores litorales para confeccionar puntas de proyectil y cuchillos. Una cuestión muy probable, más si consideramos que estas poblaciones fueron las únicas de la región que vivieron de la caza-recolección durante toda su historia precolonial, dependientes de una tecnología donde la lítica ocupó un papel protagónico por más de 10 mil años (Ballester y Clarot 2014; Mostny 1964; Núñez 1984; Salazar et al. 2015).

El estudio de los percutores nos permitirá discutir acerca de quiénes pudieron estar detrás de la explotación de un taller distante a más de $115 \mathrm{~km}$ del litoral, su organización tecnológica, estrategias de abastecimiento de materias primas y actividades de percusión dura. Lo haremos a partir de un estudio morfológico, tecnológico y

\footnotetext{
1 UMR 7041 ArScAN, Équipe Ethnologie Préhistorique, Université Paris 1 Panthéon Sorbonne, Paris, Francia. benjaminballesterr@gmail.com

2 Cuenco, Investigación y Gestión en Patrimonio Cultural, Santiago, Chile. mcrisostomo@cuenco.cl
} 
de huellas de uso realizado sobre 173 artefactos, la totalidad del conjunto identificado en el sitio. A esto hay que agregar que una fracción importante de ellos presentaba además decoraciones con pigmento rojo, un aspecto de enorme importancia arqueológica, ya que deja en evidencia una faceta desconocida del mundo de los talladores, aquella de los valores estéticos, cognitivos y simbólicos tras una práctica históricamente vista desde el frío lente de la eficiencia y productividad.

\section{Emplazamiento y Naturaleza de la Muestra}

El conjunto de percutores fue analizado integralmente in situ, sin realizar recolecciones superficiales, excavaciones o intervenciones del sitio arqueológico. La colección hace parte de un extenso taller lítico ubicado en el interior de Antofagasta ( $24^{\circ} 08^{\prime} 22^{\prime \prime} \mathrm{S} / 69^{\circ} 23^{\prime} 13^{\prime}$ 'W), en pleno corazón del desierto de Atacama, a $1.715 \mathrm{msm}$ y $115 \mathrm{~km}$ en línea recta de la costa, en la pampa Augusta Victoria y a los pies de un pequeño cerro parte de la Cordillera de Domeyko (Figura 1) (Vásquez 2009).

Luego de la identificación en terreno del Taller B, como lo hemos denominado, realizamos prospecciones lineales radiadas desde el centro hacia el exterior con la finalidad de definir sus límites, permitiéndonos establecer su perímetro y área total. Posteriormente implementamos un sistema de prospecciones sistemáticas con una intensidad definida por transectas paralelas cada $50 \mathrm{~m}$, dentro del polígono del sitio. Se prospectaron 47 transectas de $1,63 \mathrm{~km}$, con 76,61 km prospectados. Cada locus de talla fue registrado contemplando UTM, diámetro, fotografía, caracterización de materia prima, número total de piezas en superficie, además de cantidad de desechos, núcleos y percutores.

El taller se emplaza justo sobre una fuente lítica secundaria, un depósito regolítico conformado por un extenso manto superficial de nódulos con corteza (Figura 2), arrastrados gracias a una antigua red hídrica activada muy esporádicamente por eventos fuertes de lluvias que interrumpen el predominante régimen de aridez del desierto de Atacama (McKay et al. 2003). Según estudios petrográficos, los nódulos corresponden a rocas ígneas extrusivas e intrusivas, como andesitas, riolitas y dacitas, además de calcedonias (Crisóstomo y Figueroa 2016). En general presentan formas angulares, con baja erosión más que la eólica formando pátinas superficiales, de tamaño medio a pequeño con corteza.
En total registramos 301 locus de talla en una extensión de 375 ha, sin evidencias de otras materialidades aparte de la lítica que ayudaran a precisar la temporalidad del sitio (Tabla 1). Los locus se distribuyen aleatoriamente en los faldeos de dos pequeños montes que alcanzan los 1.800 $\mathrm{msm}$. Se componen únicamente de desechos líticos primarios de la etapa inicial de la cadena operativa para la confección de matrices bifaciales (algunas fracturadas en el sitio), con altos porcentajes de corteza en su anverso y de tamaños relativamente grandes, junto a núcleos descartados y trozos angulares (Figura 2). Destaca la completa ausencia de desechos secundarios, por façonnage y de retoque. Los únicos artefactos identificados en el sitio fueron los percutores. Solamente destacó una estructura semicircular de muro por amontonamiento de rocas asociados a un conjunto de eventos de talla, lugar donde habían guardados más de una decena de percutores (Figura 2).

\section{Definiciones Básicas sobre Percutores}

Un percutor es una herramienta de talla lítica cuya función es proveer la energía cinética necesaria para desprender lascas de un nódulo de roca, sea para tallar una forma predeterminada o extraer derivados a ser utilizados como artefactos (Aschero 1975; Bate 1971; Escola 1993; Inizan et al. 1995). Son empleados en labores definidas como de percusión dura, usualmente en las primeras partes de la secuencia operativa de la talla lítica (Inizan et al. 1995; Speth 1972). En este tipo de talla, el nivel de dureza y el tamaño del percutor deben ser necesariamente mayores que el de la piedra que se está trabajando, características físicas diferenciales que permiten, sumado a la fuerza del tallador y su experticia, fracturar la pieza y desprender lascas (Inizan et al. 1995).

Generalmente carecen de formatización aprovechando las propiedades naturales del soporte (Escola 1993), aunque algunos cuentan con sistemas de enmangue, sujeción o modificaciones para el resguardo de los dedos (Bate 1971; Craddock 1994). Sin embargo, las mayores modificaciones físicas se generan por su uso, como resultado de los impactos sobre el nódulo que se está trabajando, dando mayor información acerca de su utilización que de su manufactura (Escola 1993).

Escola (1993) define tres criterios por los cuales son seleccionados los soportes para percutores: (1) tamaño, (2) forma y (3) peso. Adicionalmente 


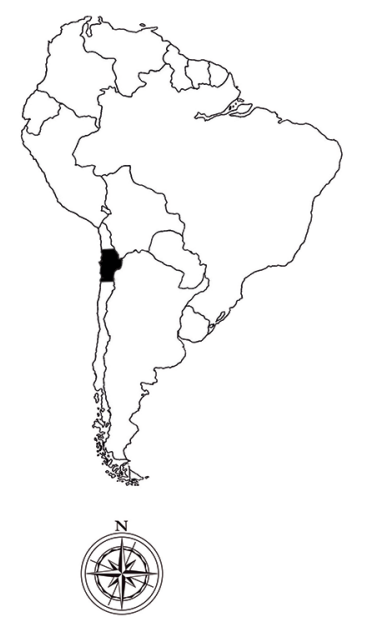

$50 \mathrm{~km}$
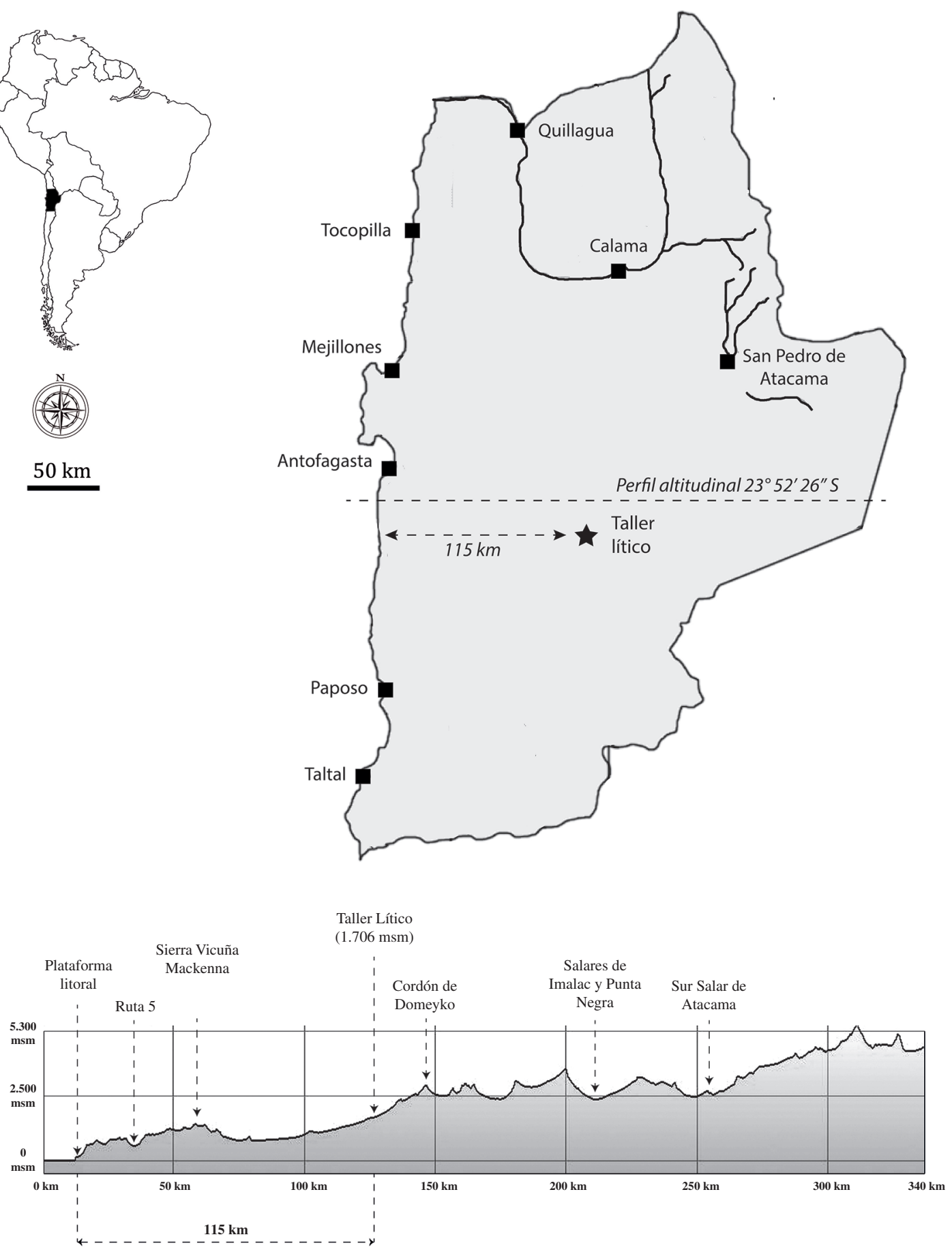

Figura 1. (Arriba) Mapa general con la ubicación del Taller B, pampa de la Región de Antofagasta. (Abajo) Corte y perfil transversal de la región donde se ubica el Taller Lítico (modificado desde McKay et al. 2013).

(Above) General map with the location of Taller B, Antofagasta Region pampa. (Below) Transversal cut and profile of the region where the lithic workshop is located (modified sensu McKay et al. 2013). 

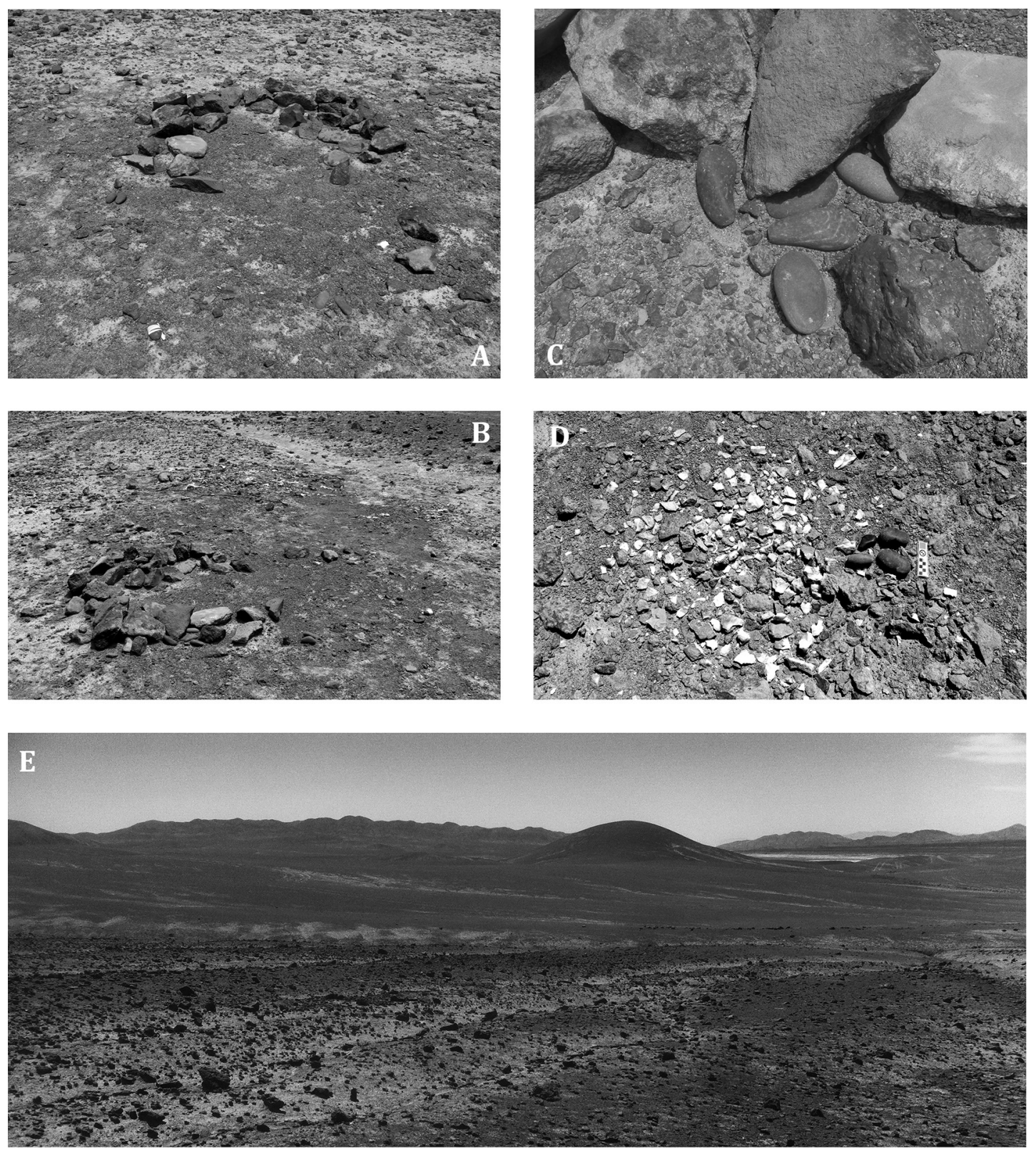

Figura 2. Locus de talla y estructura del Taller B: (A) Vista hacia el oeste de la Estructura 1, (B) vista hacia el norte de la Estructura 1, (C) detalle de posible caché de percutores en el muro de la Estructura 1; (D) Locus de talla B-201 junto a sus cuatro percutores líticos; (E) Vista general del emplazamiento del sitio.

Debitage locus and structure from Taller B: (A) west view of Structure 1, (B) North view of Structure 1, (C) review of possible hammerstone cache from the wall at Structure 1; (D) B-201 debitage locus with its four hammerstones; (E) general view of the site.

hemos agregado (4) disponibilidad y (5) dureza. El primero por ser una variable medioambiental básica que define qué se puede usar y qué no, el campo de posibilidades, incorporando además las estrategias de abastecimiento de soportes que involucren desplazamientos y transporte, un punto importante en nuestro caso de estudio. La dureza, por su parte, es un factor fundamental en la función de tallado, siempre considerada en relación a la matriz que se está trabajando. 
Tabla 1. Información general del sitio, locus de talla y percutores.

General information of the site, debitage locus, and hammerstones.

\begin{tabular}{lr}
\hline & Taller B \\
\hline Distancia de la costa $(\mathrm{km})$ & 115 \\
Altura (msm) & 1.715 \\
Superficie (ha) & 375 \\
Estructuras & 1 \\
Número de locus de talla & 301 \\
Total de piezas líticas & 34.167 \\
Locus con percutores & 71 \\
Total de percutores líticos & 173 \\
Percutores aislados & 7 \\
Lascas desde percutores & 33 \\
\hline
\end{tabular}

El tamaño y peso de los percutores son variables necesariamente ligadas entre sí. En una misma roca al aumentar el tamaño de la pieza se incrementará también su peso. Piezas más grandes y masivas son generalmente utilizadas en las etapas iniciales de las cadenas operativas del trabajo lítico, y pueden llegar a constituirse en martillos o mazos, especialmente cuando la fuente de extracción es primaria tipo afloramiento rocoso - propiamente "canteras"- desde donde se extraen bloques móviles y maniobrables (Craddock 1994; McGuire 1891; Mead 1921; Timberlake y Craddock 2013). En esta etapa la actividad es muy similar a la minería artesanal, siguiendo el mismo precepto básico. Aquí la aplicación de energía humana junto al peso del artefacto se suman como fuerza a dirigir sobre el material para extraer fragmentos de roca. En las siguientes etapas de las cadenas operativas son necesarios percutores de menor tamaño para mayor precisión en los golpes y generar fuerzas dirigidas a puntos específicos, guiando adecuadamente las fracturas. Se reduce así el peso y tamaño de los percutores, mientras que la variable forma adquiere cada vez mayor relevancia. Percutores con secciones de impacto reducidas, tamaños maniobrables y relativamente ergonómicos, facilitan golpes certeros y dirigidos para una talla precisa. Visto así, el mundo de los percutores es amplio y existen diversos tipos según la etapa de la cadena operativa.

Las huellas de uso son un excelente indicador de aspectos técnicos de su empleo, pero también de relaciones de dureza entre percutor y núcleo (Crabtree 1972; Escola 1993; Wright 1992). El emplazamiento específico de las huellas en el percutor marca el punto de impacto sobre el núcleo, dejando libre el área de sujeción del tallador. En este sentido, la concentración de desgaste o modificaciones por uso en sectores restringidos de las piezas informa sobre formas de uso regulares, con puntos de impactos definidos y estandarizados. Esta concentración de huellas puede relacionarse con la morfología de las piezas, ya que suele privilegiarse la sección con mejores cualidades técnicas para la talla. Las huellas difieren en naturaleza según el grado de fuerza involucrada en los golpes, tipo de impacto, dureza de ambas materias primas y gestos del tallador, dejando marcas en la roca que van desde leves piquetes o estrías superficiales hasta el desprendimiento de grandes lascas, o en casos más extremos, su completa fractura (Escola 1993).

\section{Metodología de Análisis}

Luego del registro general de los datos de terreno, se procedió a hacer un estudio dirigido de cada uno de los percutores. La totalidad de los análisis se realizaron in situ para no generar impactos sobre el sitio arqueológico. El análisis estuvo dirigido hacia el registro de los aspectos morfológicos, tecnológicos y huellas de uso.

Para el registro morfológico se definió cada percutor según una categoría general de forma (Figura 3A-E): (A) esferoidal u ovoidal; (B) discoidal, de sección achatada; (C) cilíndrica, de sección semicircular; (D) cilíndrica, de sección achatada; y (E) cilíndrica, de sección triangular o de tres aristas longitudinales. Su morfometría se registró midiendo un conjunto de las variables (Figura 3F): (1) diámetro mayor o largo total, de extremo a extremo; (2-3) dos diámetros de sección medial (máximo y mínimo); (4) el perímetro total del largo y (5) de la sección medial de la pieza; además del peso.

El análisis tecnológico y de huellas de uso se orientó al registro de las modificaciones por manufactura y utilización de cada pieza. Se consideraron variables como tipo de modificación, ubicación, naturaleza e intensidad de las huellas, además de rasgos decorativos, siguiendo los parámetros de Escola (1993). Para la ubicación de las huellas se definieron cuatro posibilidades: unipolar, cuando estaba en uno de los extremos; bipolar, en ambos extremos; lateral, para el borde perimetral; y plantar, en el caso de que estuviera en sus caras. 

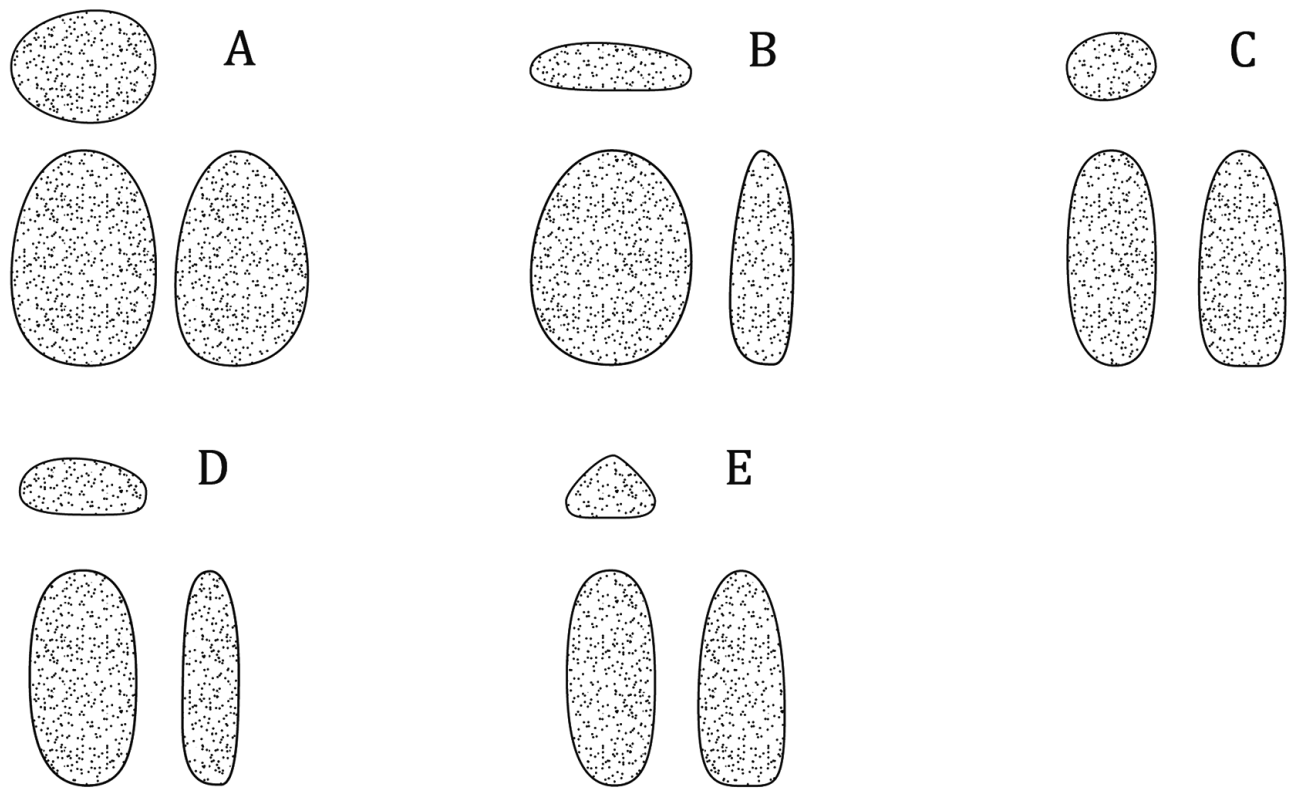

G

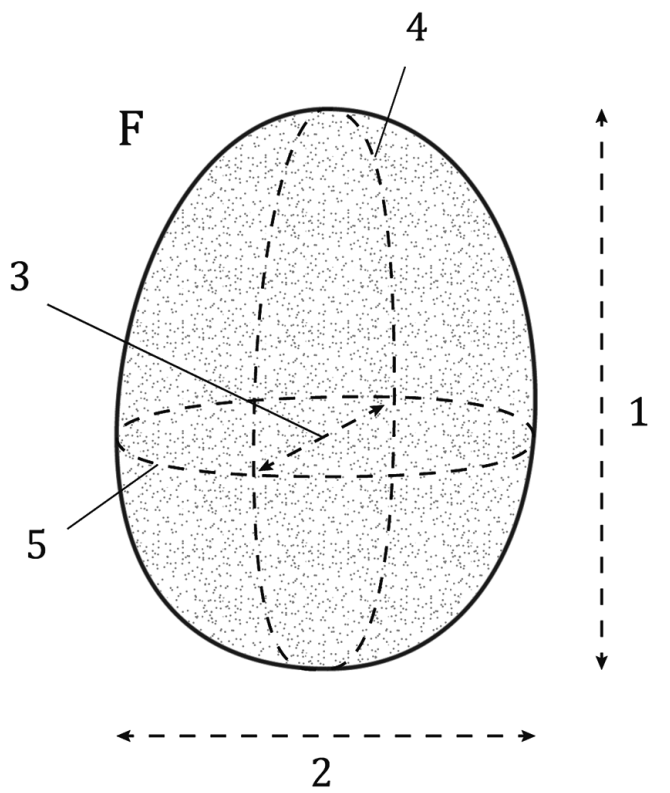

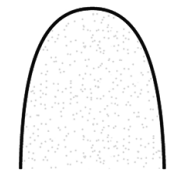

0

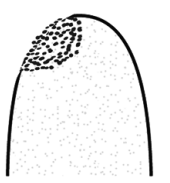

2

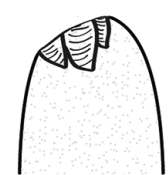

4

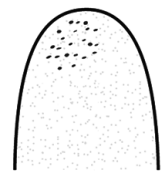

1

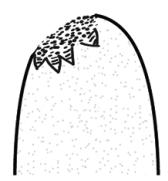

3

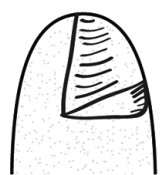

5

Figura 3. Morfología general, atributos métricos y huellas de uso de los percutores líticos: (A) Esferoidal u ovoidal, (B) Discoidal, (C) Cilíndrica sección semicircular, (D) Cilíndrica sección achatada, (E) Cilíndrica sección triangular. (F) Principales medidas de cada percutor: (1) Diámetro largo, (2) diámetro mayor sección medial, (3) diámetro menor sección medial, (4) Perímetro largo y (5) Perímetro sección medial. (G) Huellas de uso: (0) Grado 0, (1) Grado 1, (2) Grado 2, (3) Grado 3, (4) Grado 4 y (5) Grado 5.

General morphology, metric attributes, and use wear of hammerstones: (A) spheroidal or ovoid, (B) discoid, (C) cylindrical with semicircular section, $(D)$ cylindrical with oblate section, $(E)$ cylindrical with triangular section. $(F)$ Main measures of each hammerstone: (1) long diameter, (2) medial section of the larger diameter, (3) medial section of the minor diameter, (4) long perimeter, and (5) medial section perimeter. (G) Use wear: (0) Grade 0, (1) Grade 1, (2) Grade 2, (3) Grade 3, (4) Grade (4), and (5) Grade 5. 
El tipo de huellas fue definido según distintos grados de alteración de las superficies utilizadas de la pieza, sin que la numeración secuencial signifique etapas de un proceso lineal de uso y desgaste, sino solo el nivel de modificación (Figura 3G). Grado 0, superficies útiles que no presentan modificaciones o huellas visibles de uso. Grado 1, leve piqueteado o punteado superficial, sin modificaciones sustanciales de la forma original. El Grado 2, hoyuelos y piquetes más prominentes que llegaron a modificar la forma general de la pieza, aplanándola o generando un plano acentuado de desgate. El Grado 3, modificaciones del punto de impacto del artefacto, con algunas leves astilladuras o desprendimiento de fragmentos del percutor, asociado además a un machacado de la superficie fracturada. El Grado 4, astillamientos prominentes hacia las caras de los percutores, en algunos casos agrupando varios negativos laterales de extracciones, dejando los extremos de uso con filos acentuados y abruptos. El Grado 5, piezas quebradas producto de los golpes contra el soporte, eliminando el punto de impacto del percutor.

En los procesos de manufactura de los percutores se consideraron posibles modificaciones intencionales de la forma del soporte (modelamiento, adición de partes) y elementos que impliquen la alteración de sus superficie (decoraciones). Se registró su ubicación según se encontraran en una o ambas caras principales y/o en el perímetro lateral. En cuanto a posibles decoraciones se señaló su naturaleza (grabado o pintado), además de si se trataba de motivos figurativos, lineales o simples manchas.

\section{Resultados}

En el extenso taller de 375 ha los únicos artefactos presentes y asociados a los locus de talla son los percutores líticos, dando cuenta del valor específico y restringido de este espacio para sus ocupantes en el pasado. Un taller con una materialidad acotada a ese tipo de actividad laboral y productiva. Es por esto que los percutores se encuentran por lo general asociados directamente al locus de talla ( $\mathrm{n}=155 / 89,6 \%)$, a excepción de 18 de ellos $(10,4 \%)$ ubicados aislados en el paisaje o junto a la única estructura (Tabla 1). En total hay una densidad de 0,57 percutores por cada locus de talla, o en términos simples un percutor por cada dos locus, frecuencia que demuestra una alta tasa de recambio de las herramientas de talla y que probablemente no fueron reutilizados en muchos procesos de trabajo.

En relación a las variables métricas puede notarse una alta estandarización de las formas utilizadas como soporte, en primer lugar, porque se seleccionaron exclusiva y únicamente guijarros de formas redondeadas. Las cinco categorías de forma que definimos son en términos generales similares entre sí (Figura 3A-E), variando solo en aspectos métricos y en la sección medial de las piezas (semicircular, achatada o triangular). Dentro del conjunto los guijarros que tienden a formas esferoidales u ovoidales (tipo A) son los menos frecuentes $(7,5 \%)$, predominando más bien aquellos de secciones achatadas y triangulares (77\%), característicos de cierto tipo de erosión en su formación (tipos B, D y E) (Tabla 2).

La Figura 4 muestra que en general las piezas tienden a ser más largas que esferoidales, tanto desde las medidas de sus diámetros (1-3) como de sus perímetros totales (4-5), tratándose de formas más bien oblongas o cilíndricas (77\%) (Tabla 2). De igual manera grafica que sus secciones mediales son en general asimétricas y achatadas (2-3). En conjunto se puede apreciar cierto grado de estandarización de las formas escogidas para utilizar como soportes, primando las piezas alargadas, oblongas y de secciones achatadas, de rangos métricos relativamente restringidos y acotados, cuyo peso tampoco varía en gran medida (Figura 5).

Del total, solamente dos percutores $(1,17 \%)$ no contaban con huellas de uso en sus superficies, un porcentaje menor $(8,09 \%)$ las contenía únicamente en uno de sus polos, mientras que el universo restante (90,75\%) las tenía en ambos polos o extremos (Tabla 3). En ningún caso se evidenciaron huellas laterales, perimetrales o en las caras principales de las piezas, mostrando una tendencia de utilizar ciertas secciones específicas de los percutores para los impactos sobre la roca, con puntos definidos y estandarizados de acción, establecidos seguramente por gestos, formas de tomar los artefactos y cierta ergonomía compartida tras el proceso de trabajo de talla lítica.

Las huellas más comunes son las del grado 2, 4 y 3 (en ese orden), con una muy baja tasa de percutores quebrados (Tabla 3). Es interesante notar que la gran mayoría de las piezas no se encuentran descartadas por fractura y que aún disponen de cualidades tecnológicas para seguir siendo utilizadas en labores de percusión. La existencia de percutores 
Tabla 2. Síntesis numérica de los resultados obtenidos del análisis de los percutores líticos. Numerical summary of the results of the analysis of the hammerstones.

\begin{tabular}{|c|c|c|c|c|}
\hline Total de percutores & & & $\begin{array}{c}\text { Número } \\
173\end{array}$ & $\begin{array}{c}\text { Porcentaje } \\
100,00\end{array}$ \\
\hline \multirow{7}{*}{ Forma } & \multirow{5}{*}{ Tipo } & Esferoidal & 13 & 7,50 \\
\hline & & Discoidal & 26 & 15,03 \\
\hline & & Cilíndrica sección circular & 27 & 15,60 \\
\hline & & Cilíndrica sección achatada & 76 & 43,93 \\
\hline & & Cilíndrica sección triangular & 31 & 17,92 \\
\hline & \multirow[b]{2}{*}{ Simetría } & Simétrico & 100 & 57,80 \\
\hline & & Asimétrico & 73 & 42,20 \\
\hline \multirow{10}{*}{$\begin{array}{l}\text { Huellas de uso (por } \\
\text { superficie de uso) }\end{array}$} & \multirow{4}{*}{ Posición } & Ausente & 2 & 1,17 \\
\hline & & Unipolar & 14 & 8,09 \\
\hline & & Bipolar & 157 & 90,75 \\
\hline & & Perimetral & 0 & 0,00 \\
\hline & \multirow{6}{*}{ Tipo } & Grado 0 & 18 & 5,20 \\
\hline & & Grado 1 & 39 & 11,27 \\
\hline & & Grado 2 & 164 & 47,40 \\
\hline & & Grado 3 & 53 & 15,32 \\
\hline & & Grado 4 & 71 & 20,52 \\
\hline & & Grado 5 & 1 & 0,29 \\
\hline \multirow{6}{*}{ Decoración } & \multirow{4}{*}{ Ubicación } & Ausente & 145 & 83,82 \\
\hline & & Una cara & 27 & 15,61 \\
\hline & & Dos caras & 0 & 0,00 \\
\hline & & Perimetral + una cara & 1 & 0,58 \\
\hline & \multirow[b]{2}{*}{ Tipo } & Mancha & 21 & 12,14 \\
\hline & & Lineal & 7 & 4,05 \\
\hline
\end{tabular}

Tabla 3. Tipo de huellas de uso por superficie utilizada en cada percutor. Use wears types by utilized surface in each hammerstone.

\begin{tabular}{|c|c|c|c|c|c|c|c|}
\hline & & \multicolumn{6}{|c|}{ Superficie 2} \\
\hline & & Grado 0 & Grado 1 & Grado 2 & Grado 3 & Grado 4 & Grado 5 \\
\hline \multirow{6}{*}{ 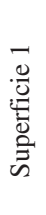 } & Grado 0 & 2 & 7 & 5 & 1 & 0 & 1 \\
\hline & Grado 1 & 7 & 6 & 16 & 3 & 1 & 0 \\
\hline & Grado 2 & 5 & 16 & 54 & 22 & 13 & 0 \\
\hline & Grado 3 & 1 & 3 & 22 & 6 & 15 & 0 \\
\hline & Grado 4 & 0 & 1 & 13 & 15 & 21 & 0 \\
\hline & Grado 5 & 1 & 0 & 0 & 0 & 0 & 0 \\
\hline
\end{tabular}

sin uso $(1,17 \%)$, otros con huellas en solo uno de los extremos $(8,09 \%)$ y algunos con marcas de baja intensidad refuerzan esta idea, por lo que detrás de su descarte debieron jugar factores que se encontraban por sobre el agotamiento de sus cualidades técnicas y potencial de uso.

La única modificación intencional de los guijarros para convertirlos en percutores fue su decoración superficial, no existiendo modelamientos o añadidura de secciones (Tabla 2). Las decoraciones son en todos los casos aditivas mediante el pintado de parte de sus superficies utilizando un pigmento rojo, sin señales de grabados o incisiones (Tabla 2). En total se registraron 28 piezas con decoración (16,19\%), 23 de ellos asociados a locus de talla, dos en la Estructura 1 y tres aislados, todos con huellas de uso unipolar $(n=3)$ o bipolar $(n=25)$, por tanto utilizados como percutores. Si bien el porcentaje de la muestra con estas expresiones pictóricas es relativamente menor, no hay que descartar posibles factores tafonómicos que pudieran haber estado involucrados en su conservación, ya que todos los artefactos en que se detectó pintura la tenían solo en una de sus dos caras principales y más 


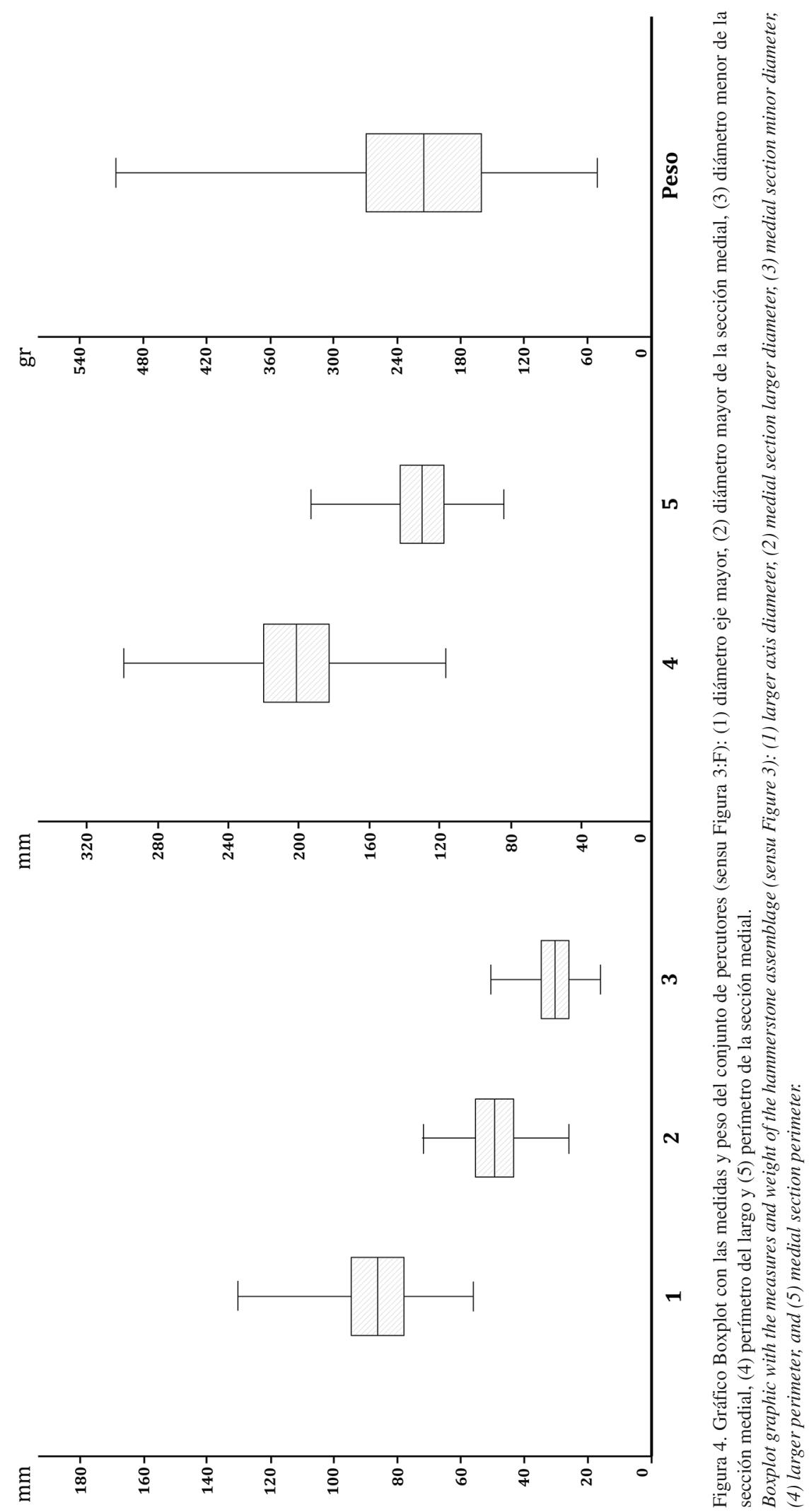




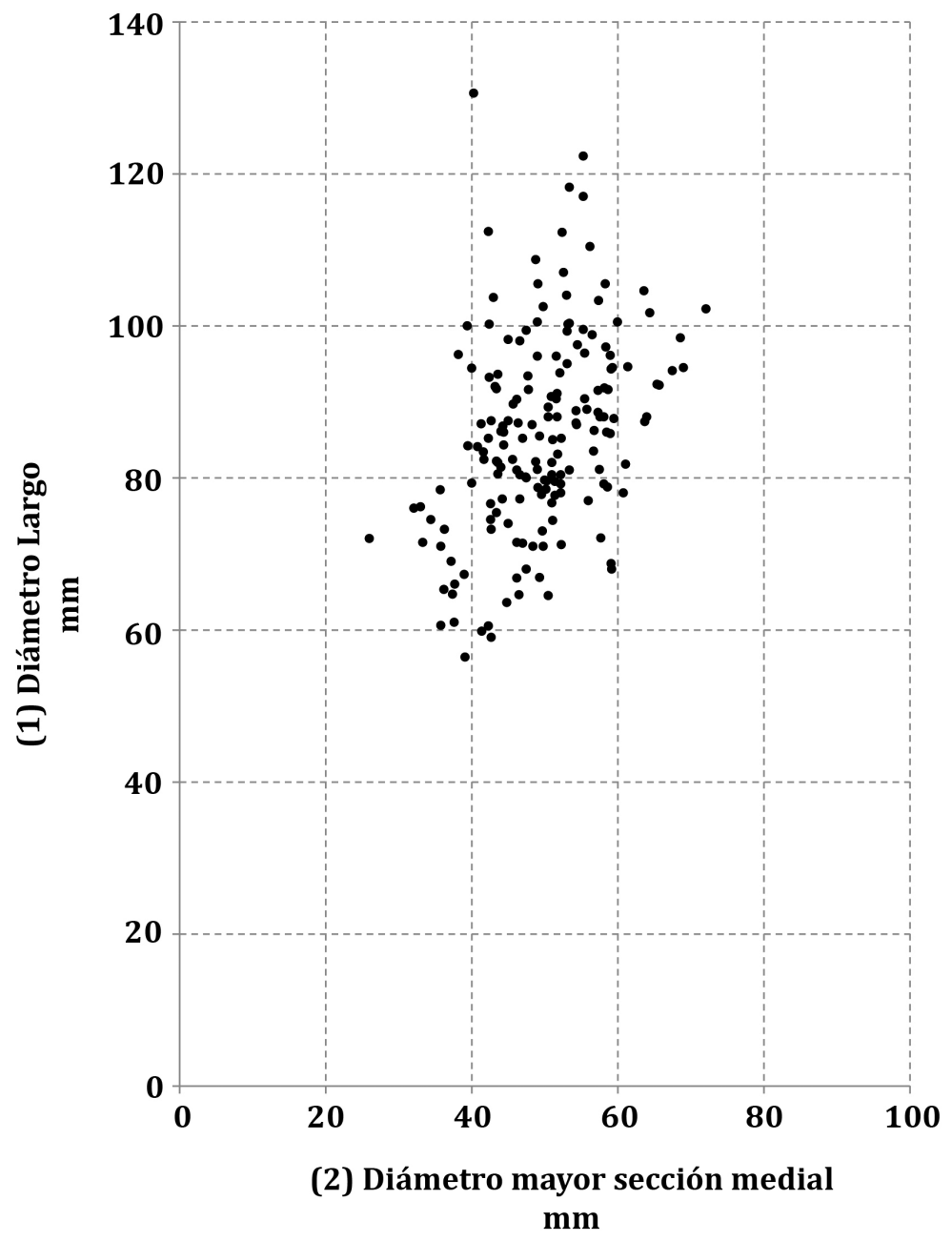

Figura 5. Gráfico de dispersión de puntos que relaciona los diámetros del largo con el diámetro mayor de la sección medial de los percutores.

Scatter plot graphic relating large diameters and medial section major diameter of the hammerstones.

extensas, justamente sobre aquella enfrentada al piso y protegida de los agentes erosivos como el sedimento desplazado por el viento. Esto implica que los percutores bien pudieron estar originalmente pintados en más de una cara y que los procesos postdepositacionales fueran los responsables de su estado actual.

Las piezas no están todas decoradas de la misma forma (Figura 6, Tabla 2). Una fracción importante no dispone de motivos definidos o distinguibles, sino más bien solo manchas o concentraciones amorfas de pigmento sobre la superficie ( $\mathrm{n}=21 / 12,14 \%)$ (Figura 6J, F). Debido a los mismos factores tafonómicos, bien podrían estas manchas haber correspondido a motivos que fueron borrados, despintados, desvanecidos y privados de su forma original, aunque tampoco puede descartarse que solo fueran pintados o manchados con el único fin de teñirlos de rojo.

Una fracción de ellos $(n=7 / 4,05 \%)$ sí exhibía motivos definidos por trazos lineales rectos, paralelos al eje principal y más largo de las piezas, recorriendo solo una de sus caras de extremo a extremo (Figura 6D, E, G, K). Los grosores de estas líneas no llegan a superar los $3 \mathrm{~cm}$ y el largo se define en función del tamaño de la pieza. Es notable que en todos los casos las líneas tengan la misma dirección, de polo a polo o de superficie de talla a superficie de talla, cruzando una de sus caras principales. 
Uno de los percutores destaca dentro de conjunto debido a un decorado más sofisticado y delicado, compuesto de un preciso pintado lineal que recorre no solo transversalmente y a lo largo una de sus caras principales, sino también el contorno de todo su perímetro o borde lateral (Figura 6A-C). Este ejemplo da cuenta el grado de complejidad y simbolismo tras estas representaciones sobre soportes móviles. Lamentablemente la cara pintada de la pieza era también aquella que se encontraba hacia abajo y protegida, por lo que es difícil saber si la otra también estaba pintada.

\section{Discusión de los Resultados}

En el taller la dispersión de percutores se encuentra definida por la concentración del locus de talla, y estos en función de la disponibilidad natural de recursos líticos superficiales. El mayor volumen de los artefactos está asociado a los locus de talla, mientras que solo una fracción menor se encuentran aislados en el paisaje. Una situación especial ocurre en la única estructura de rocas al interior del sitio (Figura 2A-C), poseyendo una concentración inusual de percutores apilados uno al lado de otro sin asociación directa al locus de talla, dando cuenta de un posible contexto de acumulación, almacenamiento o caché de estas piezas (Franco et al. 2011), situación que se vuelve más factible si agregamos que uno de ellos no presenta si quiera huellas de uso. Ante esta condición la estructura bien pudo constituir un espacio de articulación dentro del área general del taller, a modo de centro de trabajo donde se acopiaba parte de las herramientas para las actividades de talla, además del descanso o pernocte.

Es interesante que el mayor volumen de los percutores fuera descartado sin perder las cualidades técnicas para continuar su vida útil, dejados en el taller sin estar terminados. Algunos presentan huellas leves y unos pocos extremos sin evidencias de uso, situación que lleva a pensar que su descarte pudo tener que ver con factores ajenos a su potencial técnico. Varias razones pudieron existir tras la intención de no llevarse consigo los artefactos luego de la labor de talla, sea para disminuir el kit a cargar de vuelta a casa, dejarlos en el taller para reutilizarlos en una futura campaña, o marcar con artefactos un territorio propio de explotación, entre otras tantas posibilidades. Lo claro es que algunos no volvieron a ser utilizados, una fracción menor están completamente quebrados por uso (presentan golpes de impacto), y otros nunca fueron utilizados para tallar, evidenciando distintas estrategias de transporte, uso y descarte, expresión material de su organización tecnológica.

La concentrada y sectorizada ubicación de las huellas de uso en los percutores, exclusivamente en sus extremos o polos, es reflejo seguramente de una norma o pauta definida acerca de cuáles son los puntos de impacto, además de cómo emplear y manipular los artefactos. Normatividad que también se expresa en sus formas, utilizando exclusivamente guijarros tendientes a siluetas oblongas y achatadas,

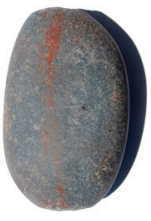

A

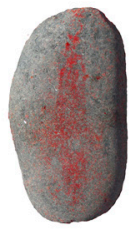

G

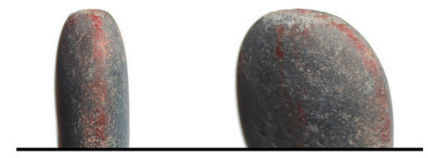

c

B

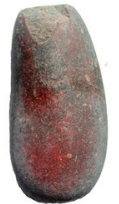

H

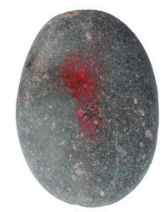

I
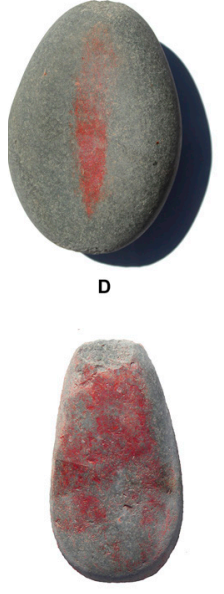

J

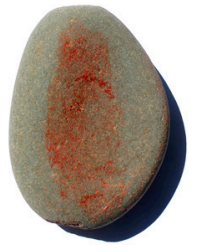

E
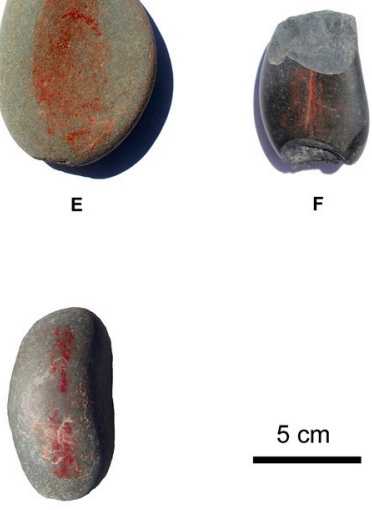

K

Figura 6. Detalle de algunos de los percutores decorados del Taller B. En los casos A-C, D, E, G y K puede apreciarse claramente el motivo lineal de la decoración.

Detail of some of the decorated hammerstones from Taller B. In cases A-C, D, E, G, and $K$ it is possible to appreciate the lineal decoration. 
de medidas y pesos relativamente regulares y uniformes. Todos estos factores apuntan a una estricta selección de soportes y un manejo estandarizado, habitual y conocido de las herramientas de talla. Un diseño común y ergonomía de los artefactos regido por cánones estilísticos y productivos compartidos.

Los guijarros utilizados no fueron obtenidos en las inmediaciones del taller. El escenario donde se emplaza el sitio se caracteriza por una red hídrica que actúa solo intermitentemente, con flujos esporádicos alimentados por aguas lluvias generadas dentro de ciclos ambientales largos (usualmente decadales). Esta situación genera un panorama geológico y lítico definido por un bajo porcentaje de clastos de tamaño medio a pequeños depositados por arrastre en la superficie del desierto, predominando las formas angulares con aristas definidas, con niveles bajos de erosión casi exclusivamente por factores eólicos (pátinas). Estas condiciones locales no son las necesarias para la formación de guijarros con el grado de redondez y pulimiento característico de los soportes utilizados para los percutores. Sus rasgos más bien, por su pulimento y cuerpo semiesferoidal, corresponden a formas generadas por procesos de erosión agresivos, por fricción constante e intensa, característicos de abrasiones por flujos de agua que arrastran constantemente las piezas generando la fricción y el movimiento necesario para la formación de las peculiares siluetas de los guijarros (Domokos y Gibbons 2012; Krumbein 1941).

Estas condiciones se presentan en sistemas fluviales y marinos, en ambos teniendo al flujo de agua como principal agente de desplazamiento (Wentworth 1922). Debido a que ambos ambientes presentan cinemáticas, dinámicas físicas y fuerzas disímiles, generan formas peculiares de guijarros, lo que permite distinguir su origen geológico según algunos de sus atributos morfológicos (Dobkins y Folk 1970; Kelly 1983). En los sistemas fluviales el desplazamiento del sedimento ocurre en un eje lineal y en un solo sentido, variando la intensidad y fuerza del transporte según la pendiente y alimentación del afluente, donde el ruedo por arrastre crea guijarros en general de formas esferoidales u ovoidales en el cual la abrasión se aplica similarmente en todas las superficies de la roca (Domokos et al. 2014; Kelly 1983). En estos casos el grado de redondeamiento del guijarro dependerá de su ubicación en el eje de descenso del curso fluvial, presentando mayor grado de pulimento hacia su sección final debido a una historia más larga de abrasión (Attal y Lavé 2009).
En las playas marinas, por el contrario, la cinemática y el flujo del agua son orquestados por el vaivén de las olas, arrastrando los sedimentos hacia afuera y hacia adentro en un movimiento bidireccional sobre la superficie de la playa (Landon 1930; Wentworth 1921, 1922). Esto genera guijarros en general de formas achatadas, discoidales y oblongas en la zona de transporte de la ola, debido a que los sedimentos más que rodar tienden a arrastrarse por una de sus superficies aplicándose toda la abrasión y fricción sobre sus caras principales (Dobkins y Folk 1970; Landon 1930). Por esto las secciones mediales de estos guijarros tienden a ser achatadas o triangulares, con caras planas, no esferoidales. Estos últimos en playas marinas suelen desplazarse fuera del área de rompimiento de la ola hacia el interior del mar a mayor profundidad gracias a su capacidad de rodar aprovechando la gravedad y pendiente (Landon 1930).

La existencia de guijarros de formas distintas en ambos ambientes es una buena herramienta para inferir su sistema de abastecimiento. Nuestra muestra se compone principalmente de guijarros de secciones achatadas y triangulares $(77 \%)$, predominando las piezas alargadas u oblongas $(77,5 \%)$ por sobre las esferoidales u ovoidales $(7,5 \%)$. Esta tendencia dice relación con procesos de abrasión y erosión de sistemas marinos, no fluviales.

Si los guijarros provienen de una formación marina, tal vez las ideas que hace más de un siglo enunciaban Max Uhle (1916, 1917) y Augusto Capdeville (Mostny 1964) acerca de la explotación de estos talleres pampinos por cazadores-recolectores litorales podría ser acertada. Así también lo han expresado otros autores posteriores, tanto desde el estudio de los talleres como de la lítica litoral (Ballester y Clarot 2014; Bird 1943; Blanco 2016; Blanco et al. 2010; Castelleti 2007; Galarce y Santander 2013; García-Albarido y Castro 2014; Núñez 1984; Peralta et al. 2010; Salazar et al. 2015). En palabras de Uhle (1917:49) luego de su excursión en la pampa de Taltal:

en medio de ella, a alturas de 2.000 metros y más, existen restos de murallas de piedra en forma de herradura (para abrigo) rodeada de millares de fragmentos de cuarzo y rodados cilíndricos llevados al lugar por el hombre para servir de instrumentos en la fabricación de sus puntas de flechas, puntas de lanzas, raspadores, etc. 
Las similitudes con el taller por nosotros estudiado son evidentes, no solo por los millares de fragmentos líticos, sino también por los guijarros o rodados cilíndricos utilizados como percutores y por la presencia de una estructura semicircular junto al taller. Tanto fue el interés de Uhle por los percutores que publica una lámina donde se aprecia claramente sus formas oblongas y achatadas, tal como las que componen el Taller B (Figura 7).

En el litoral es común la presencia de guijarros marinos utilizados como percutores (Berdichewsky 1965; Bird 1943; Durán et al. 1994/1995; GarcíaAlbarido 2012; García-Albarido y Castro 2014; Mostny 1964). En Morro Colorado justo al norte de Taltal, por ejemplo, Junius Bird (1943) describe algunas de estas piezas asegurando que se manufacturaban sobre guijarros marinos redondeados. En 2016, mientras analizamos su colección arqueológica en el American Museum of Natural History de New York, estudiamos tres de estos percutores sobre guijarros con las mismas huellas de uso en sus extremos, dos de ellos además decorados con pigmento rojo (p.ej. Figura 8). Percutores con colorante rojo son mencionados también en otros sitios costeros como Copaca 1, Caleta del Fierro 2, Guasilla 2, Caleta Errázuriz y La Chimba 13 (Durán et al. 1994/1995; García-Albarido 2012; García-Albarido y Castro 2014), demostrando una amplia distribución geográfica y temporal. Si bien algunos autores han interpretado la presencia de este colorante por el uso de los percutores además como manos para moler el pigmento (Durán et al. 1994/1995; García-Albarido 2012), la existencia de motivos lineales en las piezas de los talleres líticos interiores y la alta recurrencia de ambas expresiones hace pensar más bien en decoraciones intencionales y no solo en una respuesta funcional de su uso.

Las decoraciones lineales en algunos de los artefactos del taller interior son elocuentes y claras (Figura 6D, E, G, K), de las cuales una destaca por su mayor sofisticación pictórica (Figura 6A-C). En ella la decoración lineal atraviesa transversalmente una de sus caras y recorre todo el perímetro de su contorno, demostrando un diseño intencional y un cierto esquema de dibujo ya establecido. La línea es delicada, relativamente homogénea y cuidadosa de no quebrar la idea predefinida. Es interesante notar que los piquetes y hoyuelos polares generados producto del uso de este percutor al golpearlo contra otra roca quedaron en al menos cinco casos $(17,8 \%$ de los decorados) marcados posterior al pintado de la pieza, superponiéndose las huellas de uso a la pintura y no al revés (Figura 6C, F, H, J). Situación que se repite también en algunas piezas de la costa (p.ej. Figura 8). Esta condición refuerza la idea de que los decorados mediante pigmento rojo eran parte del proceso de creación de los percutores, una maniobra realizada a la hora de seleccionarlos y convertirlos en artefactos mucho antes de su utilización, como una manera de arrebatarles esa naturaleza y llenarlos de cultura.

Es claro que este acto de manufactura del percutor al decorarlo, o más bien el gesto de creación del artefacto, escapa a los fines puramente funcionales o productivos para impregnarle una carga estética, cognitiva y artística mucho más profunda y sustancial, como parte de su eficacia simbólica (Lévi-Strauss 1949). Una marca material visual destinada hacia una esfera de la práctica social que no tenía tanto que ver con la fría dureza, forma y eficiencia de la herramienta en el acto físico de la talla lítica. Sino más bien con un aspecto material del percutor que refleja la complejidad y multidimensionalidad de facetas en las que se desenvuelven los artefactos, aun hasta aquellos que consideramos más banales, técnicos o cotidianos (Sinclair 1995). Actos que bien pudieron también constituir marcas de propiedad sobre los artefactos (Boas 1899) o expresiones de "arte mobiliar" asociadas a objetos de trabajo (Linares 1970, 1988). Así visto, la vida social y esencia del percutor no pudo concentrarse única y exclusivamente en el tallar, al menos no ese tallar neutro y simplista, caricaturizado y minimizado en cuanto sus funciones y valores sociales, sino que además debió ser parte activa de las definiciones de sentido, distinciones simbólicas y la construcción cultural del mundo de estos talladores, y de su relación con los otros.

Los motivos lineales tan definidos presentes en este grupo de percutores nos recuerdan inmediatamente un hallazgo realizado en el litoral de Caldera hace 80 años por el naturalista Ernesto Gigoux (1936). Se trata de un conjunto de 50 valvas de lapa (Fisurella sp.) pintadas delicadamente con líneas hechas con colorante rojo que formaban seis tipos distintos de signos definidos por la mezcla de los trazos rectos a lo largo y ancho de la valva (Figura 9). La existencia de solo seis posibles combinaciones definidas y limitadas entre las líneas pintadas da cuenta de un esquema representacional y simbólico que ordenó las posibilidades de asociación entre las partes, una estructura de signos que seguramente fue compartida por un corpus social en donde las combinaciones 


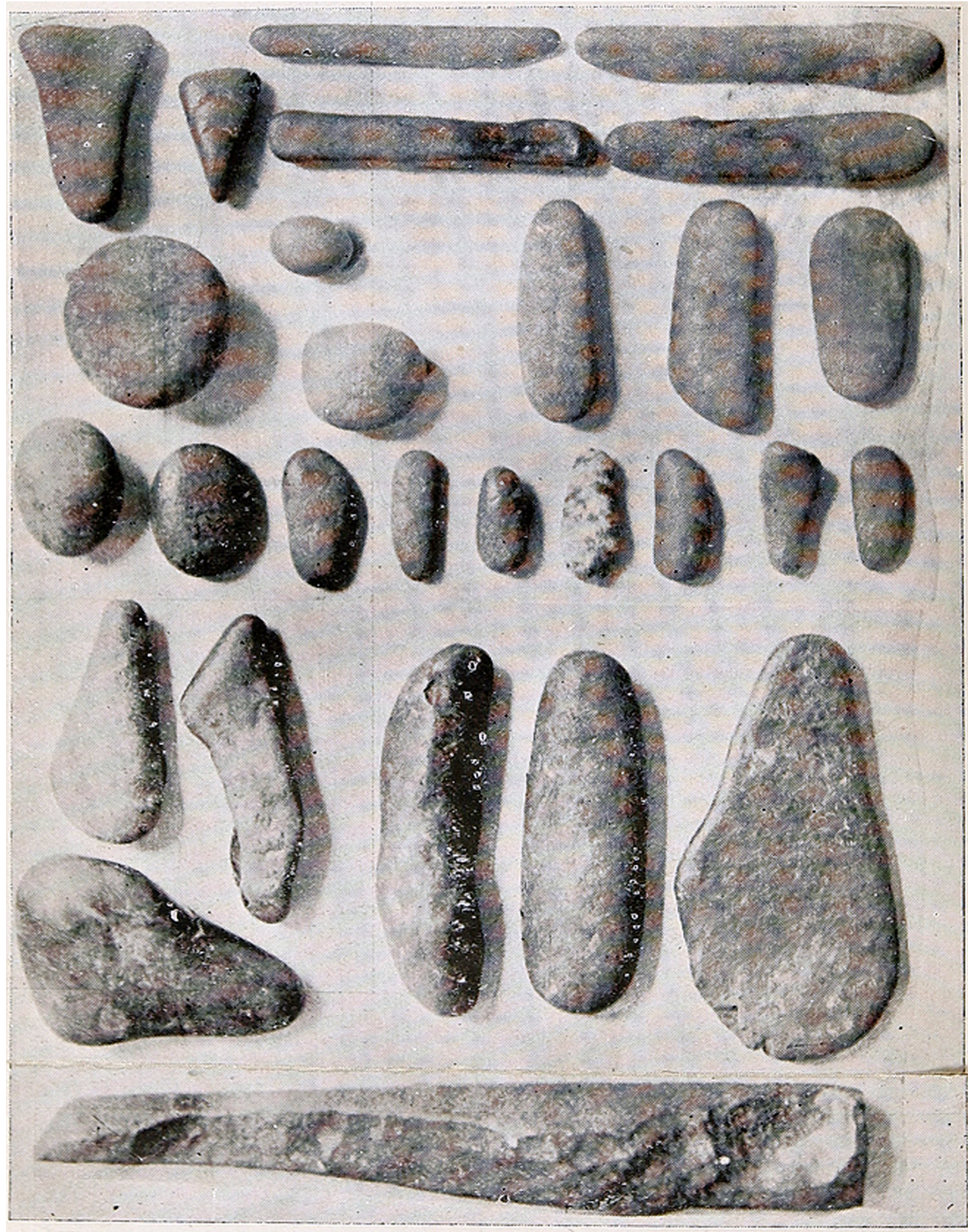

Figura 7. Guijarros fotografiados por Max Uhle en Taltal (1917:Fig. 10).

Pebbles photographs taken by Max Uhle (1917:Fig. 10) in Taltal. 


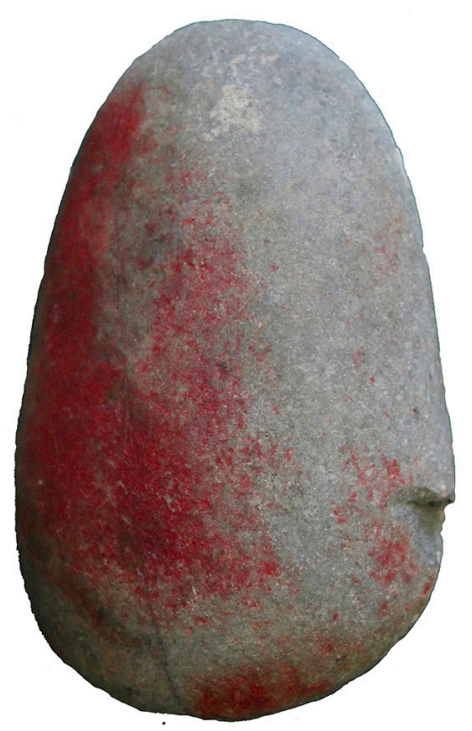

A
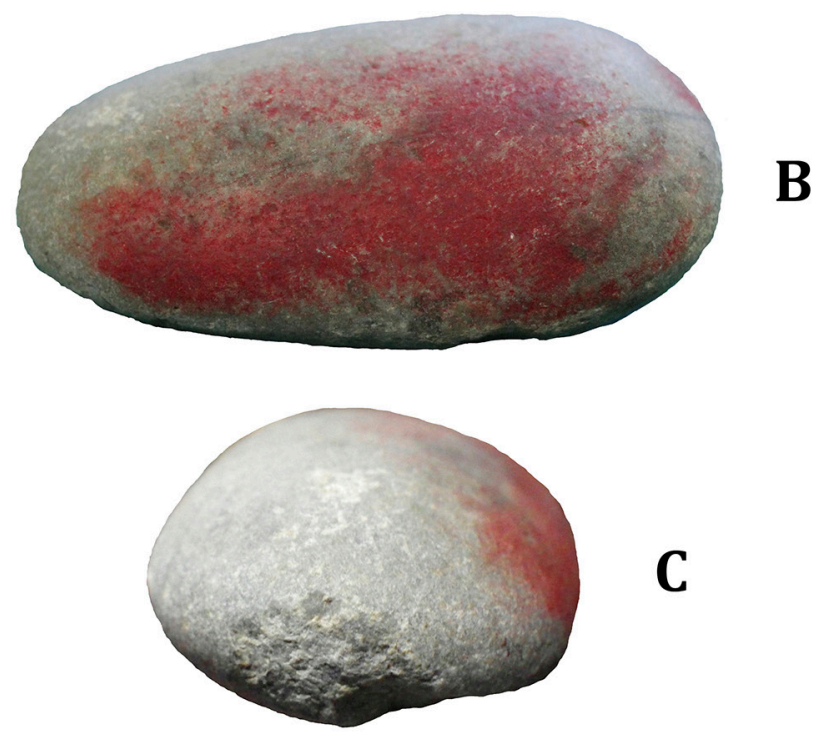

$5 \mathrm{~cm}$

Figura 8. Guijarro utilizado como percutor con pigmento rojo exterior recuperado por Junius Bird en Morro Colorado, depositado en el American Museum of Natural History de New York ( $\mathrm{N}^{\circ}$ Inv: 41.1/ 7228). (A) Vista de una de sus caras principales decorada, (B) detalle lateral donde se aprecian algunos rasgos lineales, y (C) extremo con las huellas de uso.

Pebble utilized as hammerstone with red pigment on surface recovered by Junius Bird at Morro Morado site, deposited in the American Museum of Natural History of New York (Inv: $N^{\circ} 41.1 / 7228$ ). (A) View of one of its principal decorated faces, (B) lateral lineal decoration detail, and $(C)$ use wears in its extreme.

tomaban sentido. Aunque a otra escala, pero siguiendo el mismo fundamento, la idea de decorar estos percutores con líneas pintadas debió fundarse en signos visuales y códigos simbólicos compartidos por aquellos que hacían uso y compartían con estos objetos. Entre ellos sin lugar a dudas estaban los talladores, pero también otros sujetos ajenos directamente al acto de la talla, no por eso desconocedores de la existencia de estos objetos, su virtud y naturaleza.

En ambos casos estamos frente a un arte mobiliar cargado de signos y sentidos culturales. Piezas que tienen la capacidad de desplazarse transportando ideas de la mano de sus portadores dentro de sus respectivos circuitos de movilidad, cada uno en su propio contexto y según sus valores de uso. En el caso de los percutores, aquella movilidad relacionada a la pampa y la piedra, viajando cientos de kilómetros de distancia, estableciendo un lazo estrecho entre estas piezas, las ideas que cargaban, el contexto social en el que se desenvolvían y los talladores, transformándose en ícono de una labor y de ciertos agentes sociales.

\section{¿Qué hacen Aquí, tan Lejos del Mar?}

Pensar que los talleres pampinos pudieron ser explotados por grupos de cazadores-recolectores litorales abre una serie de reflexiones sobre su vida pasada. Una de ellas tiene que ver con su modo de vida, históricamente visto como casi exclusivamente dependiente del litoral y el mar, siendo que en su tecnología y mundo material el desierto en su totalidad siempre fue protagónico. El universo de la lítica es el más evidente, pero no podemos olvidar también otros minerales, pigmentos, maderas, vegetales y la fauna silvestre, tan necesarios en su construcción cultural y reproducción social como el mar (Bittmann 1986; Blanco 2013).

El taller estudiado se emplaza a $115 \mathrm{~km}$ en línea recta del litoral, una distancia que inevitablemente implicó estrategias de viajes, planificaciones, organización tecnológica y una división del trabajo que permitiera poder llevar a cabo estas incursiones sin poner en jaque la propia reproducción de la 

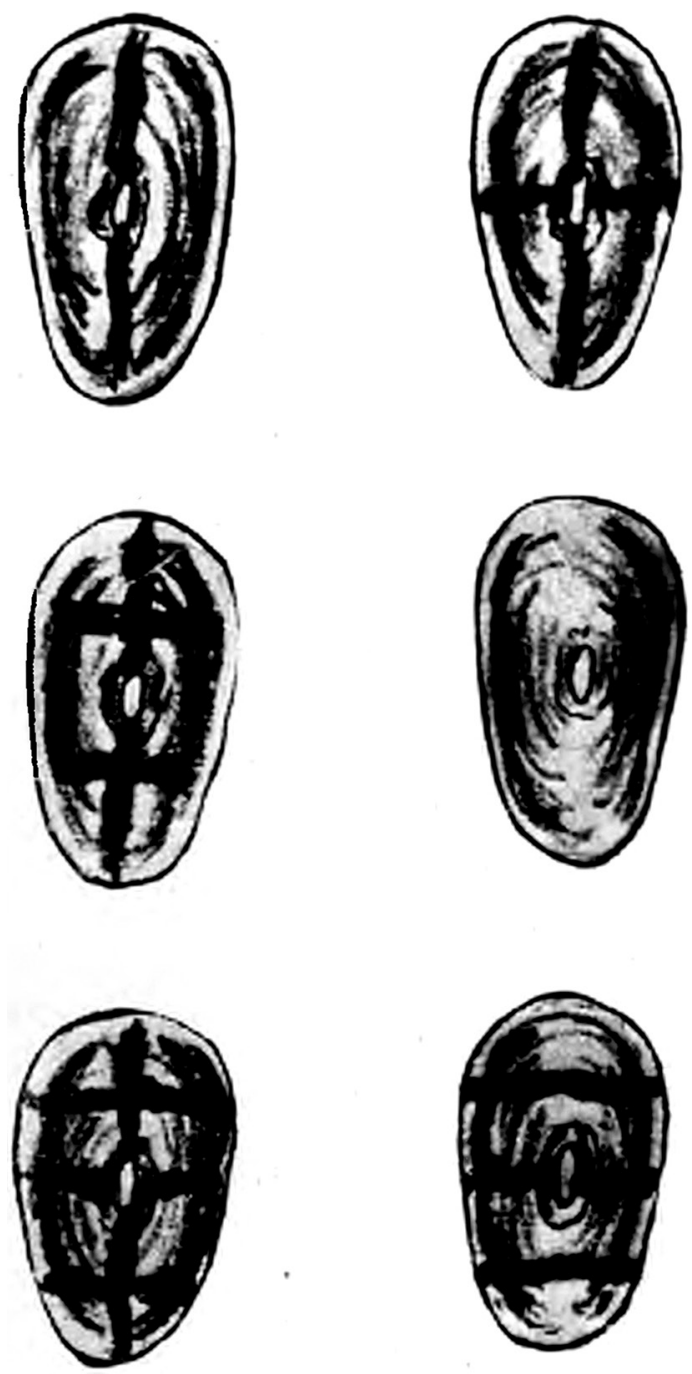

Figura 9. Serie de valvas de Fisurella sp. pintadas en seis combinaciones (Gigoux 1936:13;Lam. 1).

Series of Fisurella sp. valves painted in six combinations (Gigoux 1936:13; Plate 1).

caleta costera. Fue necesario pleno conocimiento del paisaje y ambiente desértico, mapeando geográfica y temporalmente fuentes, recursos, rutas, abrigos, climas y aguadas.

Es interesante que aun existiendo extensas fuentes líticas más cercanas a la costa (Blanco et al. 2010), los grupos se desplazaran tanto hacia el interior del desierto en travesías de varias jornadas, con altos costos de traslado y planificación. Creemos que esto no se debe a factores exclusivamente técnicos de la producción lítica, sino más bien que su abastecimiento estuvo inserto dentro de una compleja red multicausal de movimientos a lo largo y ancho del desierto (Bamforth 1991; Binford 1979; Gould y Saggers 1985), donde otros recursos como los minerales y forestales eran también importantes en la organización tecnológica, al igual que la necesidad de establecer y mantener vínculos, rutas, contactos e intercambios con poblaciones que habitaban en los valles y oasis interiores (Ballester y Gallardo 2011; Gallardo et al. 2016; Pimentel et al. 2010; 2011). Más que un lugar de paso, comprender la pampa como parte del territorio de los cazadores-recolectores litorales. Un paisaje conocido, frecuentado, habitado, trabajado, recorrido, convivido y tal vez en ciertas partes, compartido con otros.

Seguramente las aguadas del interior del desierto jugaron un papel fundamental al servir como espacio de asentamiento secundario mientras duraban las incursiones, además de servir de eje articulador para los desplazamientos interiores. Esto también porque los talleres mismos no cuentan con un registro arqueológico típico de campamentos, pero sí algunas de las aguadas más conocidas del interior, como Aguas Verdes, Agua de Varas, Aguas Blancas, Agua de la Providencia, Agua de San Guillermo, La Isla, Cachinal, Ratones, Los Sapos y El Carrizo (Cabello 2008; Darapsky 2013[1900]; Espinoza 1897; Phillipi 1860; Uhle 1917; Urrejola y Orellana 2000).

En este habitar del territorio desértico los cazadores-recolectores litorales llevaron consigo objetos, entre ellos percutores para utilizarlos en los talleres. Si los portaban es porque sabían de su ausencia en el interior, pero seguramente también porque todo buen tallador se acostumbra a su herramienta de trabajo, a su ergonomía y características físicas, convirtiéndolo en un ícono de su labor. Quién sabe, tal vez ahí radique también la intención por decorarlos. Por eso la necesidad de portar los percutores que tradicionalmente utilizaban en la costa dejándolos luego de la travesía en el taller, ya sea para no volver tan cargados hacia la costa o para aprovecharlos en un próximo viaje. Ir hacia la pampa implicaba por tanto subir cargando rocas para volver cargando rocas, subiendo hacia el interior los percutores y bajando hacia la costa los núcleos y bifaces para futuros artefactos. Un vaivén territorial que mezcló y unió ambas regiones, el litoral y la pampa, mediante el constante desplazamiento de personas junto a objetos y materias primas, la mejor evidencia hoy del complejo y extenso territorio de los antiguos cazadores-recolectores del litoral del desierto de Atacama. 
Agradecimientos: BHP Billiton proyecto EWS, FONDECYT 1160045 y FONDAP 15110006. Agradecemos a Américo Provoste, Francisco Gallardo, José Blanco, Patricio Aguilera, Marcela Sepúlveda y Sumru Aricanli, junto al American
Museum of Natural History de New York por facilitar las colecciones de Junius Bird. Adicionalmente agradecemos a los evaluadores del manuscrito y a los editores de la revista por contribuir en su publicación.

\section{Referencias Citadas}

Aschero, C. 1975. Ensayo para una clasificación morfológica de artefactos líticos aplicada a estudios tipológicos comparativos. Informe al CONICET 475, Buenos Aires.

Attal, M. y J. Lave 2009. Pebble abrasion during fluvial transport: experimental results and implications for the evolution of the sediment load along rivers. Journal of Geophysical Research 114: doi:10.1029/2009jf001328

Ballester, B. y A. Clarot 2014. La Gente de los Túmulos de Tierra. Marmot Impresores, Santiago.

Ballester, B. y F. Gallardo 2011. Prehistoric and historic networks on the Atacama Desert coast (northern Chile). Antiquity 85:875-889.

Bamforth, D. 1991. Technological organization and huntergatherer land use: A California Example. American Antiquity 56(2):216-234

Bate, L. 1971. Material lítico: metodología de clasificación. Noticiario Mensual del Museo Nacional de Historia Natural 181/182:3-24.

Berdichewsky, B. 1965. Exploración arqueológica en la costa de la provincia de Antofagasta. Antropología 2:3-30.

Binford, L. 1979. Organization and formation processes: Looking at curated technologies. Journal of Anthropological Research 35:255-273.

Bird, J. 1943. Excavations in northern Chile. Anthropological Papers of the American Museum of Natural History 38(4):173-318.

Bittmann, B. 1986. Recursos naturales renovables de la costa del norte de Chile: Modos de obtención y uso. En Etnografía e Historia del Mundo Andino: Continuidad y Cambio, editado por S. Masuda, pp. 269-334. Universidad de Tokio, Tokio.

Blanco, J. 2013. La Extracción Prehispánica de Recursos Minerales en el Internodo Quillagua-Costa, desierto de Atacama. Memoria para optar al título de Arqueólogo, Universidad de Chile, Santiago.

Blanco, J. 2016. Introducción al mundo lítico y mineral de los cementerios de túmulos de la costa de Atacama. Casos de estudio, asociaciones e inferencias preliminares. En Monumentos Funerarios de la Costa del desierto de Atacama: Contribuciones al Intercambio de Bienes e Información entre CazadoresRecolectores Marinos (Norte de Chile), editado por F. Gallardo, B. Ballester y N. Fuenzalida. ICIIS, SCHA, Santiago, en prensa.

Blanco, J., M. de la Maza y C. Rees 2010. Cazadores recolectores costeros y el aprovisionamiento de recursos líticos. Perspectivas interpretativas de los eventos de talla en el desierto absoluto. Werkén 13:45-68.

Boas, F. 1899. Property marks of Alaskan Eskimo. American Anthropologist 1(4):601-613.
Cabello, G. 2008. Aspectos culturales y arqueológicos proyecto reapertura Mina Guanaco II Región de Antofagasta. Informe SEIA, Santiago.

Castelleti, J. 2007. Patrón de Asentamiento y Uso de Recursos a través de la Secuencia Ocupacional Prehispánica en la Costa de Taltal. Tesis para optar al grado de Magíster en Arqueología, Universidad Católica del Norte, Antofagasta.

Crabtree, D. 1972. An Introduction to flintworking. Occasional Papers of the ldaho State University Museum 28:1-98.

Craddock, B. 1994. Notes on stone hammers. Bulletin of the Peak District Mines Historical Society 12(3):28-30.

Crisóstomo, E. y F. Figueroa 2016. Estudio petrográfico y de proveniencia de rocas de la zona de Antofagasta (S23 $42^{\prime}-\mathrm{S} 24^{\circ} 12^{\prime}$ ). Manuscrito en posesión de los autores.

Darapsky, 1. 2013 [1900]. El Departamento de Taltal (Chile), Morfología del Terreno y sus Riquezas. Gobierno de Chile. Cámara Chilena de la Construcción, Santiago.

Dobkins, J. y R. Folk 1970. Shape development on Tahiti-Nui. Journal of Sedimentary Petrology 40(4):1167-1203.

Domokos, D. y G. Gibbons 2012. The evolution of pebble size and shape in space and time. Proceedings of the Royal Society a Mathematical, Physical and Engineering Sciences 468(2146):3059-3079.

Domokos, D., D. Jerolmack, A. Sipos y Á. Török 2014. How River Rocks Round: Resolving the Shape-Size Paradox. PloS One 9:1-7.

Durán, A., I. Kuzmanic y N. Montenegro 1994/1995. Caleta Errázuriz, un área de asentamientos de pescadores del Período Tardío en la Segunda Región. Boletín Ocasional del Museo Regional de Antofagasta 2:7-21.

Escola, P. 1993. De percusión y percutores. Palimpsesto, Revista de Arqueología 3:33-51.

Espinoza, E. 1897. Jeografía Descriptiva de la República de Chile. Imprenta i Encuadernación Barcelona, Santiago.

Franco, N., A. Castro, N. Cirigliano, M. Martucci y A. Acevedo 2011. On cache recognition: An example from the area of the Chico river, Patagonia, Argentina. Lithic Technology 36:39-55.

Galarce, P. y G. Santander 2013. Contextos líticos de asentamientos arcaicos en la costa de Taltal (II Región, Chile). Estudios Atacameños 46:5-26.

Gallardo, F., B. Ballester y N. Fuenzalida 2016. Monumentos funerarios y flujos de información social costera. En Monumentos Funerarios de la Costa del Desierto de Atacama: Contribuciones al Intercambio de Bienes e Información entre Cazadores-Recolectores 
Marinos (Norte de Chile), editado por F. Gallardo, B. Ballester y N. Fuenzalida. ICIIS, SCHA, Santiago, en prensa.

García-Albarido, F. 2012. Estrategias de Subsistencia en Cobija durante el Periodo Intermedio Tardio y el Tawantinsuyu. Aproximación desde la Funcionalidad de los Instrumentos Líticos. Memoria para optar al Título de Arqueólogo, Universidad de Chile, Santiago.

García-Albarido, F. y V. Castro 2014. Los pescadores tardíos de Cobija, depósitos domésticos y estrategias de subsistencia. Estudios Atacameños 49:45-68.

Gigoux, E. 1936. Contribución a la conchiliología arqueológica. Boletín del Museo Nacional 15:3-13.

Gould, R. y S. Saggers 1985. Lithic procurement in Central Australia: A closer look at Binford's idea of embeddedness in Archaeology. American Antiquity 50:117-136.

Inizan, M., M. Reduron, H. Roche y J. Tixier 1995. Technologie de la Pierre Taillée. C.R.E.P., Meudon.

Kelly, P. 1983. Roundness in river and beach pebbles: a review of recent research with some implications for schools' fieldwork. Geography 68:25-30.

Krumbein, W. 1941. The effects of abrasion on the size, shape and roundness of rock fragments. The Journal of Geology 49(5):482-520.

Landon, R. 1930. An analysis of beach pebble abrasion and transportation. The Journal of Geology 38(5):437-446.

Le Paige, G. 1970. Industrias Líticas de San Pedro de Atacama. Editorial Orbe, Santiago.

Lévi-Strauss, C. 1949. L'efficacité symbolique. Revue de l'Histoire des Religions 135(1):5-27.

Linares, E. 1970. El Arte mobiliar en el sur del Perú. Revista Española de Antropología Americana 5:77-98.

Linares, E. 1988. Arte mobiliar con tradición rupestre en el sur del Perú. Rock Art Research 5:54-65.

McGuire, J. 1891. The stone hammer and its various uses. American Anthropologist 4(4):301-312.

Mckay, C., E. Friedmann, B. Gómez-Silva, L. Cáceres-Villanueva, D. Andersen y R. Landheim 2003. Temperature and moisture conditions for life in the extreme arid region of the Atacama Desert: four years of observations including the El Niño of 1997-1998. Astrobiology 3(2):393-406.

Mead, R. 1921. Prehistoric mining in western South America. Natural History 21:453-456.

Mostny, G. 1964. Arqueología de Taltal: epistolario de Augusto Capdeville con Max Uhle y otros. Fondo Histórico y Bibliográfico José Toribio Medina, Santiago.

Núñez, L. 1984. Secuencia de asentamientos prehistóricos del área de Taltal. Futuro 8:28-76.
Peralta, P., C. González, C. Westfall y G. Santander 2010. Primeras aproximaciones sobre la arqueología de Pampa Austral: explotación y tecnología lítica al interior de la región de Atacama (Chile). Actas del XVII Congreso Nacional de Arqueología Chilena, Tomo I, pp. 297-306. Ediciones Kultrún, Valdivia.

Pimentel, G., C. Rees, P. de Souza y P. Ayala 2010. Estrategias de movilidad del período formativo en la depresión intermedia, desierto de Atacama. Actas del XVII Congreso Nacional de Arqueología Chilena, pp. 1353-1364. Ediciones Kultrún, Valdivia.

Pimentel, G., Ch. Rees, P. de Souza y L. Arancibia 2011. Viajeros costeros y caravaneros. Dos estrategias de movilidad en el período Formativo del Desierto de Atacama, Chile. En En Ruta. Arqueología, Historia y Etnografía del Trafico Sur Andino, editado por L. Núñez y A. Nielsen, pp. 43-81. Grupo Editor Encuentro, Córdoba.

Phillipi, R. 1860. Viage al Desierto de Atacama Hecho de Orden del Gobierno de Chile. Librería Eduardo Anton, Halle.

Salazar, D., V. Figueroa, P. Andrade, H. Salinas, L. Olguín, X. Power, S. Rebolledo, S. Parra, H. Orellana y J. Urrea 2015. Cronología y organización económica de las poblaciones arcaicas de la costa de Taltal. Estudios Atacameños 50:7-46.

Sinclair, A. 1995. The technique as a symbol in Late Glacial Europe. World Archaeology 27(1):50-62.

Speth, J. 1972. Mechanical basis of percussion flaking. American Antiquity 37:34-60.

Timberlake, S. y B. Craddock 2013. Prehistoric metal mining in Britain: the study of cobble stone mining tools based on artefact study, ethnography and experimentation. Chungara Revista de Antropología Chilena 45:33-59.

Uhle, M. 1916. Sobre la Estación Paleolítica de Taltal. Revista Chilena de Historia y Geografía 20(24):47-66.

Uhle, M. 1917. Sobre la estación Paleolítica de Taltal. Publicaciones del Museo de Etnología y Antropología 1:31-50.

Urrejola, C. y M. Orellana 2000. Explotación de Recursos Líticos de la zona desértica al interior de Taltal. Libro de Resúmenes del XV Congreso Nacional de Arqueología Chilena. Universidad de Tarapacá, Arica.

Vásquez, M. 2009. Informe de patrimonio cultural proyecto ampliación sistema de transmisión eléctrico Minera Escondida. Ingendesa, Santiago.

Wentworth, C. 1921. Quantitative Studies of the Shapes of Pebbles. Master of Science Thesis, State University of Iowa, Iowa.

Wentworth, C. 1922. The shapes of beach pebbles. United States Geological Survey Professional Paper 730(C):75-83.

Wright, K. 1992. A Classification System for Ground Stone Tools from the Prehistoric Levant. Paléorient 18(2):53-81. 